\title{
Primary neuroendocrine breast carcinomas: a retrospective analysis and review of literature
}

This article was published in the following Dove Press journal:

OncoTargets and Therapy

18 January 2017

Number of times this article has been viewed

\author{
Xin Yang' \\ Youde $\mathrm{Cao}^{2}$ \\ Chen Chen' \\ Lin Liu' \\ Cheng Wang' \\ Shengchun Liu' \\ 'Department of Endocrine and Breast \\ Surgery, The First Affiliated Hospital \\ of Chongqing Medical University, \\ ${ }^{2}$ Department of Pathology, Chongqing \\ Medical University, Chongqing, \\ People's Republic of China
}

Background: Primary neuroendocrine breast carcinomas (NEBCs) are a rare type of breast carcinomas that lack comprehensive recognition, including the clinicopathological features, therapeutic strategies, and prognostic significance. The aim of this retrospective analysis is to present and analyze our own data of primary NEBCs.

Materials and methods: We retrospectively reviewed the medical records from 2005 to 2015 in The First Affiliated Hospital of Chongqing Medical University, Chongqing, People's Republic of China to obtain a cohort of breast carcinoma patients who were confirmed to have primary NEBC by histopathology. The detailed clinical data along with histopathology, treatment, and follow-up aspects were gathered for analysis.

Results: This retrospective analysis included 19 patients with a histopathological diagnosis of primary NEBC from 2005 to 2015 . Their mean age was 59.2 years (ranging from 17 to 82 years). The majority of patients (15/19) focused on stages I and II. Of the 15 patients, 14 were positive for estrogen receptor, and 11 were positive for progesterone receptor. For neuroendocrine markers, the expression rates were $8 / 19,14 / 18,12 / 14$, and $2 / 6$ for chromogranin A, synaptophysin, neuron-specific enolase, and CD56, respectively. All operable patients except the one stage M1 underwent a surgery and 4/18 had axillary lymph node metastasis. Chemotherapy was performed in $12 / 19$, and endocrine therapy in $8 / 10$. With a median follow-up of 59.2 months, only 2 cases progressed after postoperative systemic therapy.

Conclusion: The understanding of NEBC is limited due to its rarity. More evidence should be provided to enhance the understanding of $\mathrm{NEBC}$, especially for diagnosis, treatment, and prognosis.

Keywords: primary neuroendocrine breast carcinomas, diagnosis, therapy, follow-up

\section{Introduction}

Neuroendocrine carcinomas (NECs) are a cluster of rare and heterogeneous neoplasms, and they are widely distributed throughout the whole human body, including the stomach, intestine, pancreas, adrenal, thyroid, breast, and among other areas. ${ }^{1,2}$ Most NECs occur in the gastroenteropancreatic system or respiratory tracts. ${ }^{3,4}$ The primary neuroendocrine breast carcinomas (NEBCs) are reported to have a very low incidence, accounting for $\sim 1 \%$ of all breast carcinomas. ${ }^{5}$ Invasive breast carcinomas with neuroendocrine differentiation were first described by Feyrter and Hartmann in $1963 ;{ }^{6}$ they found that this kind of breast carcinomas showed morphological features similar to neuroendocrine tumors of the gut and lung. In 1977, Cubilla and Woodruff reported the first series of primary carcinoid of the breast including 8 patients; ${ }^{7}$ this rare kind of cohort has been gradually increasingly recognized. In 2003, the World Health Organization (WHO) classification of breast tumors explicitly defined and classified NEBC; establishing that the neuroendocrine markers were detected by immunohistochemical staining in $>50 \%$ of the tumor cell population, is the unique requisite for the diagnosis of NEBC. ${ }^{8}$ The current 2012 WHO classification
Correspondence: Shengchun Liu Department of Endocrine and Breast Surgery, The First Affiliated Hospital of Chongqing Medical University, I Youyi Road, Yuanjiagang, Yuzhong District, Chongqing 400016, People's Republic of China

Tel +862389018463

Fax +8623890 III 22

Email liushengchun1968@163.com
OncoTargets and Therapy 2017:10 397-407

397

Dovepress if in 0 (c) 1 (i) 12017 Yang et al. This work is published and licensed by Dove Medical Press Limited. The full terms of this license are available at https://wwww.dovepress.com/terms.php hereby accept the Terms. Non-commercial uses of the work are permitted without any further permission from Dove Medical Press Limited, provided the work is properly attributed. For permission for commercial use of this work, please see paragraphs 4.2 and 5 of our Terms (https://www.dovepress.com/terms.php). 
of tumors subdivides NEBC into 3 groups: well-differentiated neuroendocrine tumors, poorly differentiated NECs or small cell carcinomas, and invasive breast carcinomas with neuroendocrine differentiation. ${ }^{9}$ Due to the rareness of primary NEBC, most of the available knowledge was from case reports and reviews, very few were researches with small sample sizes. ${ }^{7,10-13}$ In addition, a standard management of these tumors has not been established so far to date. Therefore, we present our own data about 19 NEBC patients including the clinical and pathological features, therapeutic strategies, and prognostic significance, hoping to contribute to offer more evidence for recognition of NEBC, especially for diagnosis, treatment, and prognosis.

\section{Patients and methods}

\section{Patients}

We retrospectively reviewed the medical records of the breast carcinoma patients who were diagnosed as breast carcinomas and had received treatment from 2005 to 2015 in The First Affiliated Hospital of Chongqing Medical University, Chongqing, People's Republic of China. Then, we allowed a series of patients confirmed to NEBC by histopathology to enroll in our analysis. Complete information of the NEBC patients, such as general information (including name, gender, age, and contact information), physical examination, imaging character, time of final diagnosis, surgical procedures, histopathology and immunohistochemistry characteristics, systemic adjuvant treatment, and follow-up outcome were collected by consulting the medical records and in consultation with the patients. This study was approved by the ethics committee from The First Affiliated Hospital of Chongqing Medical University, who deemed written informed consent not necessary due to the retrospective nature of the research.

\section{Diagnostic}

The mammography and ultrasonography of breast were performed for further diagnosis. All lesions were diagnosed as Breast Imaging-Reporting and Data System category 5. Several cases had other imaging examinations such as magnetic resonance imaging (MRI) or positron emission tomographycomputed tomography (PET-CT). However, the gold standard for diagnosing NEBC was histopathology, including the core biopsy, intraoperative frozen, and postoperative pathological examination.

\section{Surgical procedures}

The surgical procedures included the breast-conserving surgery, the radical mastectomy, and the modified radical mastectomy. In addition, patients were staged according to the seventh edition of the AJCC Cancer Staging Manual. ${ }^{14}$

\section{Immunohistochemistry}

The histological slides were reviewed and classified according to the 2012 WHO classification. ${ }^{9}$ Several important indexes that were correlated with breast cancer, such as estrogen receptor (ER), progesterone receptor (PR), human epidermal growth factor receptor 2 (HER-2), Ki-67 proliferation index, and oncoprotein P53, were detected by immunohistochemical staining. ER and PR were considered positive if $>1 \%$ of tumor cells were stained, and HER-2 was considered positive if immunohistochemical staining was 3+. Overexpression of HER-2 genes in fluorescent in situ hybridization (FISH) was also identified as HER-2 positive. Ki67 was identified as highly expressed if $>14 \%$ tumor cells were stained. We also investigated the expression of the neuroendocrine markers by immunohistochemical staining, including chromogranin A (CgA), synaptophysin (Syn), neuron-specific enolase (NSE), and CD56. At least one mentioned neuroendocrine marker was positive in immunohistochemical staining. ${ }^{8}$

\section{Adjuvant therapy and follow-up}

For patients enrolled in our analysis, we got their detailed treatment strategy and follow-up information by contacting them and consulting the medical records. We mainly got the information about whether they had comprehensive treatments, including operation, chemotherapy, radiotherapy, and/or endocrine therapy, and whether regular follow-up was carried out to assess the prognosis conditions.

\section{Results}

\section{The clinical characteristics of all primary NEBC patients at diagnosis}

From 2005 to 2015, a total of 19 NEBC patients meeting the diagnostic criteria were enrolled in our study for further analysis. All patients were women, and the median age was 61 years (ranging from 17 to 82 years, mean age 59.2 years). All patients visited our hospital due to a palpable breast mass, and then they carried out several assistant examinations for further diagnosis, such as mammography and breast ultrasonography. The lump sizes ranged from 8 to $150 \mathrm{~mm}$ in greatest dimension. The location appeared in the left breast in 11 patients $(57.9 \%)$ and right breast in the remaining 8 patients (42.1\%). They were finally diagnosed as NEBC by pathological examination. Of these patients, $18 \mathrm{NEBC}$ 
patients were operable and underwent operation as soon as they were confirmed; 1 patient without surgery was found to have distant metastasis at diagnosis. Among these surgery patients, only 4 of 18 patients had axillary lymph node metastasis, and the metastasis rates were $2 / 15,2 / 16,11 / 12$, and 4/13, respectively. According to the pathological tumor node metastasis (pTNM) staging system of AJCC, ${ }^{14}$ except for 1 patient who was unable to be staged because her breast mass was removed outside of our hospital and we failed to get her initial clinical data, 1 patient with distant metastasis at diagnosis was stage IV, 2 of 19 patients were stage III and the residual 15 patients were stage I to II (Table 1).

\section{The immunohistochemical of all primary NEBC patients}

Except 4 patients who were unknown about the status of ER and PR, of the remaining included 15 NEBC patients, ER was expressed in 14 patients (93.3\%) and PR was expressed in 11 patients (73.3\%). No available data showed HER-2 was positive in immunohistochemistry or FISH. Ki67 was highly expressed $(>14 \%)$ in 4 of 10 . For neuroendocrine markers, all 19 patients had detected $\mathrm{CgA}$, while only 18 patients had detected Syn, 14 patients had detected NSE, and 6 patients had detected CD56. As a result, 8 of 19 (42.1\%) were CgA positive, 14 of 18 (77.8\%) were Syn positive, 12 of 14 (85.7\%) were NSE positive, and 2 of $6(33.3 \%)$ were CD56 positive, as listed in Table 2.

\section{Adjuvant therapy}

For 18 operable patients, only 1 case with local advanced disease received neoadjuvant chemotherapy in order to reduce the lesions' size and remove all lesions successfully, so that they could get a long-term local control (Table 3 ). The one stage M1 also received neoadjuvant chemotherapy. In addition, apart from 2 patients without information of postoperative therapy, 11 patients had undergone postoperative chemotherapy, while 5 patients older than 75 years did not receive chemotherapy on account of they were so old that

Table I The clinical information of primary NEBC patients at diagnosis

\begin{tabular}{|c|c|c|c|c|c|c|c|c|c|}
\hline Number & Gender & $\begin{array}{l}\text { Age } \\
\text { (years) }\end{array}$ & Location & $\begin{array}{l}\text { Diagnosis date, } \\
\text { month/year }\end{array}$ & $\begin{array}{l}\text { Single/multiple } \\
\text { lesions }\end{array}$ & $\begin{array}{l}\text { Tumor } \\
\text { size }(\mathrm{mm})\end{array}$ & $\begin{array}{l}\text { Surgical } \\
\text { treatment }\end{array}$ & $\begin{array}{l}\text { Lymph node } \\
\text { (LN) }\end{array}$ & Stage \\
\hline I & Female & 61 & Left & $01 / 2015$ & Single & 14 & $\begin{array}{l}\text { MRA + SLNB + } \\
\text { ALND }\end{array}$ & $2 / 15$ & II \\
\hline 2 & Female & 77 & Left & $08 / 2015$ & Single & 15 & MRA + ALND & $0 / 11$ & 1 \\
\hline 3 & Female & 17 & Left & $06 / 2014$ & Multiple (2) & 33 and 18 & No & $\begin{array}{l}\text { Bilateral neck, left } \\
\text { supraclavicular } \\
\text { and mediastinum } \\
\text { LN, pleura }\end{array}$ & IV \\
\hline 4 & Female & 57 & Left & $03 / 2014$ & Single & 35 & Mastectomy + SLNB & $0 / 1$ & II \\
\hline 5 & Female & 64 & Left & $03 / 2012$ & Single & 16 & MRA + ALND & $0 / 13$ & I \\
\hline 6 & Female & 65 & Left & II/20I I & Single & 24 & MRA + ALND & $0 / 18$ & II \\
\hline 7 & Female & 45 & Left & $|\mathrm{I} / 20| \mathrm{I}$ & Single & 8 & MRA + ALND & $0 / 14$ & I \\
\hline 8 & Female & 46 & Right & 05/20II & Single & 31 & $M R A+A L N D$ & $2 / 16$ & II \\
\hline 9 & Female & 43 & Right & $10 / 2006$ & Single & 30 & MRA + ALND & $0 / 8$ & II \\
\hline 10 & Female & 58 & Right & $04 / 2009$ & Single & 24 & $\begin{array}{l}\text { MRA + ALND } \\
\text { subcutaneous }\end{array}$ & $1 \mathrm{I} / \mathrm{I} 2$ & III \\
\hline 11 & Female & $4 I$ & Right & $03 / 2010$ & Multiple (3) & Max: 10 & $\begin{array}{l}\text { Mastectomy + } \\
\text { ALND + breast } \\
\text { reconstruction }\end{array}$ & $4 / 13$ & II \\
\hline 12 & Female & 79 & Left & $12 / 2009$ & Single & 20 & MRA + ALND & $0 / 11$ & 1 \\
\hline 13 & Female & 82 & Right & $07 / 2008$ & Single & $\begin{array}{l}\text { I30 (with } \\
\text { ulceration) }\end{array}$ & Mastectomy & $0 / 2$ & III \\
\hline 14 & Female & 53 & Left & I I/2007 & Single & 75 & MRA + ALND & $0 / 17$ & II \\
\hline 15 & Female & 69 & Right & $05 / 2007$ & Single & 15 & MRA + ALND & $0 / 30$ & I \\
\hline 16 & Female & 77 & Left & $03 / 2008$ & Single & 45 & MRA + ALND & $0 / 17$ & II \\
\hline 17 & Female & 50 & Right & $06 / 2005$ & Single & 15 & MRA + ALND & $0 / 13$ & I \\
\hline 18 & Female & 65 & Right & $07 / 2005$ & Single & Unknown & MRA + ALND & $0 / 17$ & Unknown \\
\hline 19 & Female & 76 & Left & $12 / 2005$ & Single & 50 & $M R A+A L N D$ & $0 / 13$ & II \\
\hline
\end{tabular}

Abbreviations: NEBC, neuroendocrine breast carcinoma; MRA, modified radical mastectomy; SLNB, sentinel lymph node biopsy; ALND, axillary lymph node dissection. 
Table 2 The immunohistochemistry of primary NEBC patients

\begin{tabular}{|c|c|c|c|c|c|c|c|c|c|}
\hline Number & ER & PR & HER-2/FISH & CgA & Syn & NSE & CD56 & Ki67 (\%) & P53 (\%) \\
\hline I & $P$ & $\mathrm{~N}$ & $(2+) / \mathrm{N}$ & $\mathrm{N}$ & $P$ & $P$ & $\mathrm{~N}$ & 20 & $<5$ \\
\hline 2 & $P$ & $P$ & $\mathrm{~N}$ & $P$ & $P$ & $\mathrm{~N}$ & $\mathrm{~N}$ & 5 & $\mathrm{~N}$ \\
\hline 3 & $\mathrm{~N}$ & $\mathrm{~N}$ & None & $\mathrm{N}$ & $P$ & None & $P$ & 80 & $P$ \\
\hline 4 & $P$ & $P$ & $\mathrm{~N}$ & $P$ & $P$ & None & $\mathrm{N}$ & 3 & $\mathrm{~N}$ \\
\hline 5 & $P$ & $P$ & $\mathrm{~N}$ & $\mathrm{~N}$ & $\mathrm{~N}$ & $\mathrm{P}$ & None & $<5$ & $P$ \\
\hline 6 & $P$ & $P$ & $(2+) / \mathrm{N}$ & $\mathrm{N}$ & $P$ & $P$ & None & 80 & 50 \\
\hline 7 & $P$ & $P$ & $(2+) / \mathrm{N}$ & $N$ & $\mathrm{~N}$ & $P$ & None & $<3$ & $P$ \\
\hline 8 & $P$ & $P$ & $\mathrm{~N}$ & $\mathrm{~N}$ & $P$ & $\mathrm{P}$ & None & 50 & 5 \\
\hline 9 & $P$ & $P$ & $\mathrm{~N}$ & $P$ & $P$ & None & None & None & $\mathrm{N}$ \\
\hline 10 & $P$ & $\mathrm{~N}$ & $\mathrm{~N}$ & $P$ & $P$ & None & $N$ & None & $\mathrm{N}$ \\
\hline II & $P$ & $P$ & $\mathrm{~N}$ & $P$ & $\mathrm{~N}$ & $\mathrm{P}$ & None & 10 & 5 \\
\hline 12 & $P$ & $\mathrm{P}$ & $\mathrm{N}$ & $\mathrm{N}$ & $P$ & $P$ & None & 5 & $\mathrm{~N}$ \\
\hline 13 & None & None & None & $P$ & $P$ & $\mathrm{~N}$ & None & None & None \\
\hline 14 & $\mathrm{P}$ & $\mathrm{P}$ & $(2+) /$ none & $\mathrm{N}$ & $P$ & $P$ & None & None & $N$ \\
\hline 15 & $\mathrm{P}$ & $\mathrm{P}$ & $\mathrm{N}$ & $P$ & $P$ & $\mathrm{P}$ & $\mathrm{P}$ & None & $\mathrm{N}$ \\
\hline 16 & None & None & None & $P$ & $\mathrm{P}$ & None & None & None & None \\
\hline 17 & None & None & None & $\mathrm{N}$ & None & $\mathrm{P}$ & None & None & None \\
\hline 18 & $\mathrm{P}$ & $\mathrm{N}$ & $\mathrm{N}$ & $\mathrm{N}$ & $\mathrm{N}$ & $P$ & None & None & $\mathrm{N}$ \\
\hline 19 & None & None & None & $\mathrm{N}$ & $P$ & $P$ & None & None & None \\
\hline
\end{tabular}

Abbreviations: NEBC, neuroendocrine breast carcinoma; ER, estrogen receptor; PR, progesterone receptor; HER-2, human epidermal growth factor receptor 2; FISH, fluorescent in situ hybridization; CgA, chromogranin A; Syn, synaptophysin; NSE, neuron-specific enolase; P, positive; N, negative.

they were difficult to endure postoperative chemotherapy. However, within these 11 patients who received postoperative chemotherapy, 2 patients did not finish the entire planned chemotherapy because of the unbearable adverse reaction. The specific chemotherapy program of every patient is listed in Table 3.
For radiotherapy, only 3 of 19 patients were recommended; 1 of them was a young patient with multiple lesions and distant metastasis, 2 other patients were middle-aged women with $>3$ lymph node metastasis, but we failed to collect radiotherapy data of one of them because we did not contact the patient (Table 3).

Table 3 The adjuvant therapy and clinical follow-up of primary NEBC patients

\begin{tabular}{|c|c|c|c|c|c|c|c|}
\hline Number & Neochemotherapy & Chemotherapy & Radiotherapy & $\begin{array}{l}\text { Endocrine } \\
\text { therapy }\end{array}$ & $\begin{array}{l}\text { Follow-up } \\
\text { (months) }\end{array}$ & $\begin{array}{l}\text { Recurrence and } \\
\text { metastasis }\end{array}$ & Survival \\
\hline I & No & Yes, EC-T & Not required & No & 15.5 & No & Yes \\
\hline 2 & No & No & Not required & Yes, exemestane & 16.4 & No & Yes \\
\hline 3 & Yes, EP & No & Yes & Not required & 22.9 & $\begin{array}{l}\text { Yes, bilateral neck, left } \\
\text { supraclavicular and } \\
\text { mediastinum LN, pleura }\end{array}$ & Yes \\
\hline 4 & No & Yes, TEC* & Not required & Yes, letrozole & 25.3 & No & Yes \\
\hline 5 & No & Yes, TC & Not required & Yes, anastrozole & 49.5 & No & Yes \\
\hline 6 & No & Yes, TEC* & Not required & Yes, anastrozole & 53.6 & No & Yes \\
\hline 7 & No & Yes, TEC & Not required & Yes, tamoxifen & 53.9 & No & Yes \\
\hline 8 & No & Yes, TT"C & Not required & Yes, exemestane & 59.4 & No & Yes \\
\hline 9 & No & Yes, TP & Not required & Yes, tamoxifen & 114 & Yes, brain & Yes \\
\hline 10 & Yes, TAC & Yes, TAC & Yes & Yes, anastrozole & 85 & Yes, bone and liver & Yes \\
\hline II & No & Yes, TEC & Unknown & Unknown & 73.4 & Unknown & Unknown \\
\hline 12 & No & No & Not required & No & 57.7 & No & Death \\
\hline 13 & No & No & Not required & Unknown & 52.4 & No & Death \\
\hline 14 & No & Yes, CEF & Not required & Unknown & 101.5 & Unknown & Unknown \\
\hline 15 & No & Yes, CT" $\mathrm{F}$ & Not required & Unknown & 107.3 & Unknown & Unknown \\
\hline 16 & No & No & Not required & Unknown & Unknown & Unknown & Unknown \\
\hline 17 & No & Unknown & Not required & Unknown & Unknown & Unknown & Unknown \\
\hline 18 & No & Unknown & Not required & Unknown & Unknown & Unknown & Unknown \\
\hline 19 & No & No & Not required & Unknown & Unknown & Unknown & Unknown \\
\hline
\end{tabular}

Notes: $T^{\#}$ : pirarubicin (THP). *Not finished entire planned chemotherapy.

Abbreviations: NEBC, neuroendocrine breast carcinoma; E, epirubicin; C, cyclophosphamide; T, docetaxel; F, fluorouracil (5-Fu); P, cis-platinum; LN, lymph node. 
By consulting the medical record and asking patients, we found that only 8 women received endocrine therapy and the selection of medicines depended on their menstrual status. In total, 1 patient was negative in hormone receptor and did not require endocrine therapy and 2 patients refused to receive endocrine therapy. The other 8 patients had no available endocrine therapy data (Table 3 ).

\section{Post-therapy surveillance and follow-up}

With a median follow-up of 59.2 months (ranging from 15.5 to 114), 2 of the patients died due to nonbreast cancer causes, 7 patients were lost to follow-up, and the remaining 10 patients were still alive. Of the 10 alive women, 7 survived without recurrence and metastasis, 1 of 10 was staged M1 at the preliminary diagnosis, and only 2 of 10 cases progressed after systemic therapy.

One patient was a 58-year-old woman with disease of the right breast, and 11/12 confirmed axillary lymph node metastasis by surgery. She was readmitted to our hospital due to the abnormal central nervous system symptoms. The PET-CT scan recognized isolated occupied lesions at her left frontal lobe, without other suspicious lesions. Given her NEBC history that she was diagnosed before 3.6 years, she was highly suspected of brain metastases and received an operation to remove the intracranial tumor. Eventually, the postoperative pathological examination confirmed to be the metastatic NEC. After the operation, she has continued to take the medication of anastrozole, up to now, without new suspicious lesions.

Another patient was a 43-year-old woman who developed bone and hepatic metastases during the follow-up. Initially, she underwent a modified radical mastectomy with axillary lymph node dissection and a complete postoperative adjuvant chemotherapy. Subsequently, the patient continued with endocrine therapy until the ilium bone metastases were detected after a follow-up of 32 months. No evidence of additional suspicious lesion in the whole body was noted by PET-CT. The patient carried out 6 cycles of chemotherapy and local radiotherapy of the ilium, as well as diphosphonate for 1 year. Meanwhile, the endocrine therapy was continued. Unfortunately, over a period of 38 months, after she was confirmed as NEBC for 70 months, she undertook a spiral computed tomography (CT) of the abdomen (Figure 1), and the result revealed that the density of liver parenchyma was diffusely reduced, with extensive round-like higher density lesions in plain scan and multiple nodular enhancement in enhanced CT of the liver. Meanwhile, the blood tumor marker carcinoembryonic antigen (CEA) of this patient was significantly increased. A lot of evidence tended toward the diagnosis of hepatic metastases. For further treatment, an operation of ovarian ablation followed by anastrozole therapy was performed for her progressive disease, combined with capecitabine. After 7 months (in April 2013), the CT of the abdomen showed that the hepatic lesions noteworthy decreased (Figure 2), as well as the level of CEA due to the effect of anastrozole and capecitabine therapy, and hence, the therapy was continued. The reinspection of CT of the abdomen and circulating CEA in May 2014 suggested an improvement of the patient's disease (Figure 3). However, in October 2014, the patient was readmitted to our hospital because of advance of the bone and hepatic metastatic lesions (Figure 4A and B) and increase in the CEA. As a result, the patient received chemotherapy again, and the hepatic lesions had obviously narrowed after chemotherapy (Figure 4C and D). Later, capecitabine was used as maintenance therapy, and the disease in bone and liver was has been stable so far.

\section{Discussion}

Primary NEBCs are an uncommon entity, and were first described by Feyrter and Hartmann in $1963 .{ }^{6}$ In spite of several sporadic reports, not until 2003 when the WHO defined and classified it, did the public have a real sense of recognition of NEBC. However, enhanced attention was paid to NEBC over the past few years; there were still some challenges in the management of NEBC, including the diagnosis, treatments, and long-term outcome.

Imaging examination such as mammography, ultrasonography, or MRI could provide some helpful imaging findings, but there was still a degree of difficulty in the diagnosis of NEBC by imaging examination; a number of NEBC patients appeared to have signs of common breast carcinomas such as ill-defined margins, irregular shapes, calcification, and so on, and other patients' breast carcinomas might show regular shapes and well-circumscribed margins just like benign lesions. ${ }^{15,16}$ As previously reported, the imaging characteristics of NEBC in our study were also variable on radiography (Tables S1 and S2), but the majority of NEBC tended to present poor features in mammography or ultrasonography.

It is widely accepted that pathological examinations are gold standards for the diagnosis of carcinomas. Microscopically, the tumor cells in well-differentiated neuroendocrine tumors might present spindle and plasmacytoid appearances, occasionally with clear cell features, while the tumor cells in poorly differentiated NECs and small cell carcinomas might appear with high nuclear/cytoplasmic ratios, an active mitotic rate, smoky dense chromatin, areas of necrosis, and frequent lymphovascular emboli. ${ }^{9,17}$ However, primary 

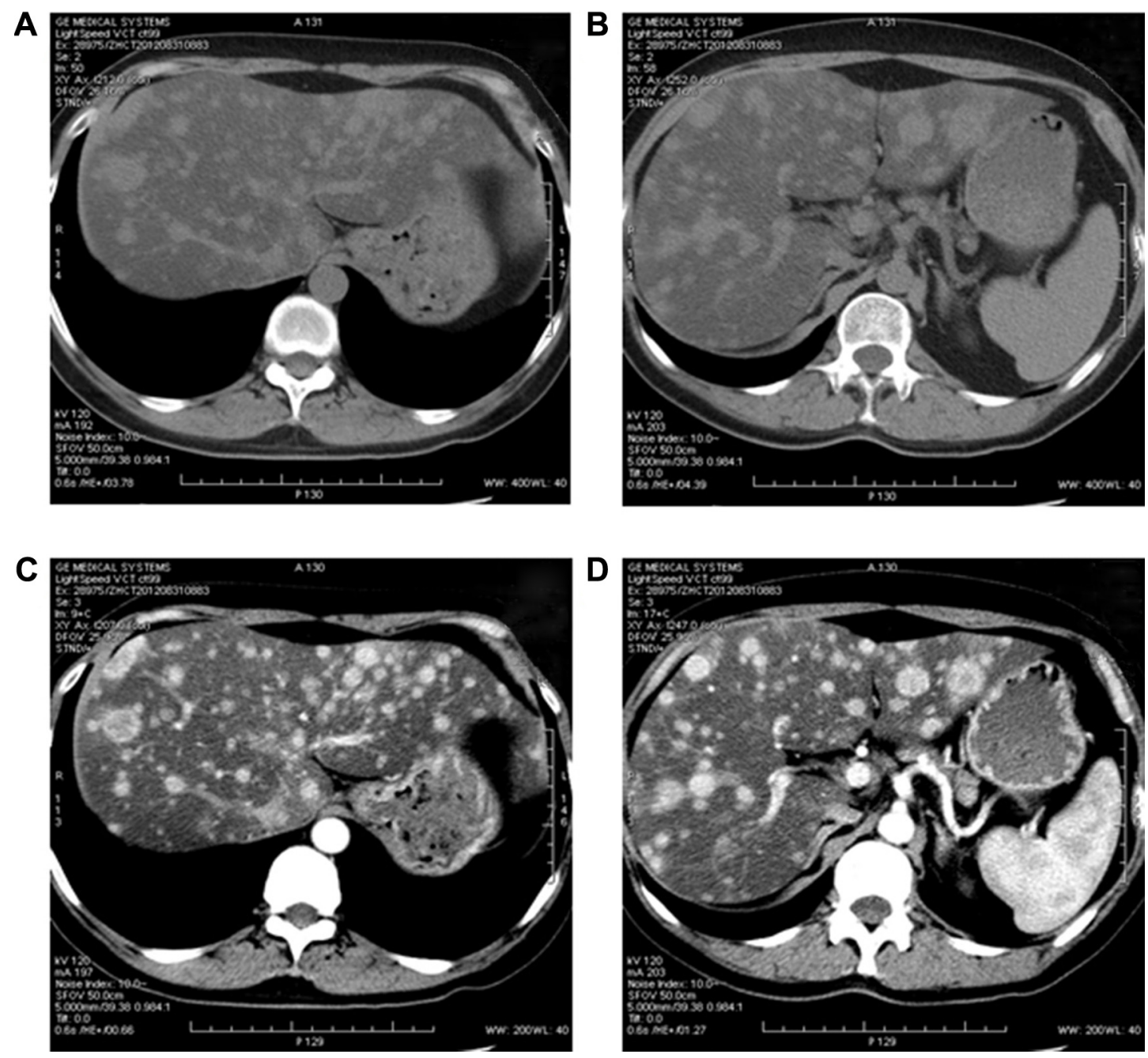

Figure I CT image of the patient with hepatic metastasis in September 2012, 70 months after the initial surgical treatment.

Notes: (A and B) The image of plain scan showed that the density of liver parenchyma was diffusely reduced, and extensive round-like higher density lesions in the liver. (C and D) Enhanced CT revealed multiple nodular enhancement in liver.

Abbreviation: CT, computed tomography.

NEBCs were not easily recognized initially just depend on routine microscopic morphology and immunohistochemistry features due to mixed growth patterns. ${ }^{13}$ Although the WHO Working Group defined NEBC as a unique cohort that showed morphological features similar to neuroendocrine tumors of the gastrointestinal tract and lung, ${ }^{8}$ a number of studies reported that some nonspecial or special breast carcinomas also presented neuroendocrine differentiation. ${ }^{18-20}$ Furthermore, the 2012 WHO Working Group acknowledged that this $50 \%$ cut-off, which was a requirement in 2003 , was conceptually arbitrary and reached an agreement on incorporating this group in NEBC without the requirement for expression of neuroendocrine markers in at least $50 \%$ of tumor cell population. ${ }^{9}$ Therefore, the current classification of NEBC is well-differentiated neuroendocrine tumors, poorly differentiated NECs or small cell carcinomas, and invasive breast carcinomas with neuroendocrine differentiation. This makes more challenging the diagnosis of NEBC especially for invasive breast carcinomas with neuroendocrine differentiation, and it suggests that particularly immunohistochemical staining for neuroendocrine markers including $\mathrm{CgA}$, Syn, NSE, and CD56 is necessary for recognizing this infrequent type of breast carcinomas. ${ }^{5,21}$ In agreement with earlier studies, NEBC tended to present hormone receptors (ER and/or PR) and absent HER-2., ${ }^{5,22,23}$ However, positivity of ER and/or PR alone was not sufficient to confirm primary NEBC because the hormone receptors were not exclusive to the mammary gland..$^{24,25}$ In the diagnosis of primary NEBC, metastasis NECs presenting as a breast lump should be excluded and an in situ component and/or positive immunohistochemical reactivity for CK7 and mammaglobin support a primary breast origin. ${ }^{24,26-28}$ 

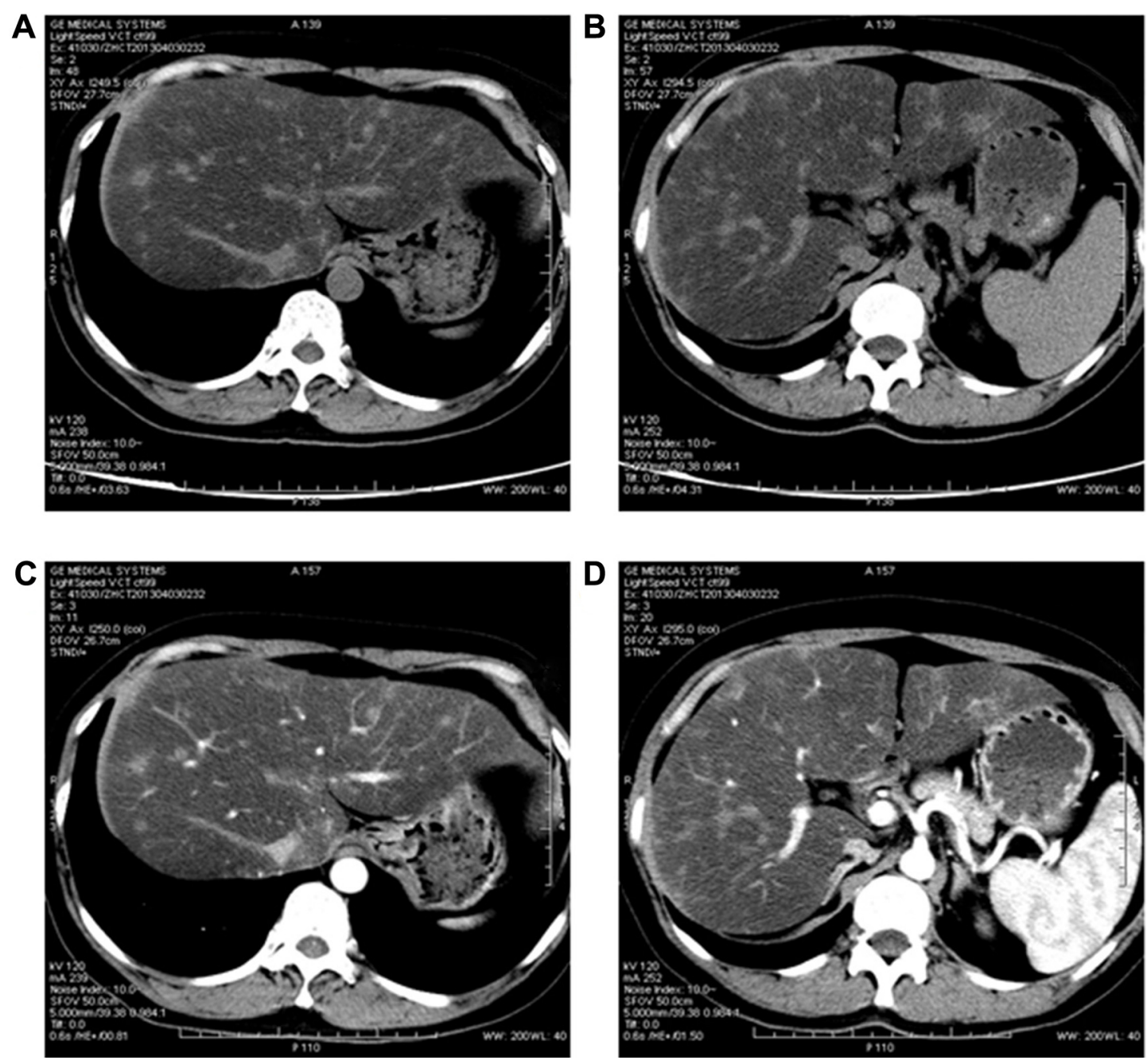

Figure 2 Post-therapy abdominal CT of the patient with hepatic metastasis in April 2013.

Note: Over a period of 7 months of treatment, both (A and $\mathbf{B})$ plain scan and (C and $\mathbf{D})$ enhanced CT showed that the hepatic lesions were gradually decreased. Abbreviation: CT, computed tomography.

Primary NEBCs were reported to be more common in elderly women. ${ }^{5,10,29,30}$ In our study, the age of NEBC patients ranged from 17 to 82 years, and the mean age was 59.2 years, which was in accordance with previous reports. All operable patients except the one who was stage M1 received surgery, and the benefits were obvious. Given still lack of a standard treatment protocol for this kind of uncommon carcinomas, current treatment protocol of primary NEBC was similar to that of invasive breast carcinomas. ${ }^{10,12,22,29}$ Surgery resection should always be considered as the first line of treatment. Endocrine therapy had been proved to be crucial to the hormone receptor-positive breast tumors, however, whether there was equally important effect of endocrine therapy for NEBC coming from a different origin, especially for NEBC patients with high expression of hormone receptor, was yet to reach a consensus. But several reports presented that these adjuvant systemic treatments including chemotherapy, radiotherapy, and endocrine therapy might play an important role and should be performed according to individuality of the patients with NEBC. ${ }^{31,32}$ Moreover, several publications reported that somatostatin and its analogs might be of help for primary NEBC with scintigraphic-confirmed somatostatinreceptor expression. ${ }^{23,33}$ But in our study, none of the patients received treatment of somatostatin and its analogs.

The prognosis of primary NEBC was equally inconsistent. Primary NEBCs were reported to be associated with worse long-term outcomes compared to primary invasive breast carcinomas. ${ }^{12}$ Similarly, a population-based study from the Surveillance, Epidemiology, and End Results (SEER) database showed that NEBCs were an aggressive breast carcinoma type with significantly shorter overall survival (OS) and disease-specific survival (DSS) than nonspecial invasive breast carcinoma. ${ }^{30}$ To the contrary, few studies demonstrated a better prognosis in NEBC patients. ${ }^{21,34,35}$ 

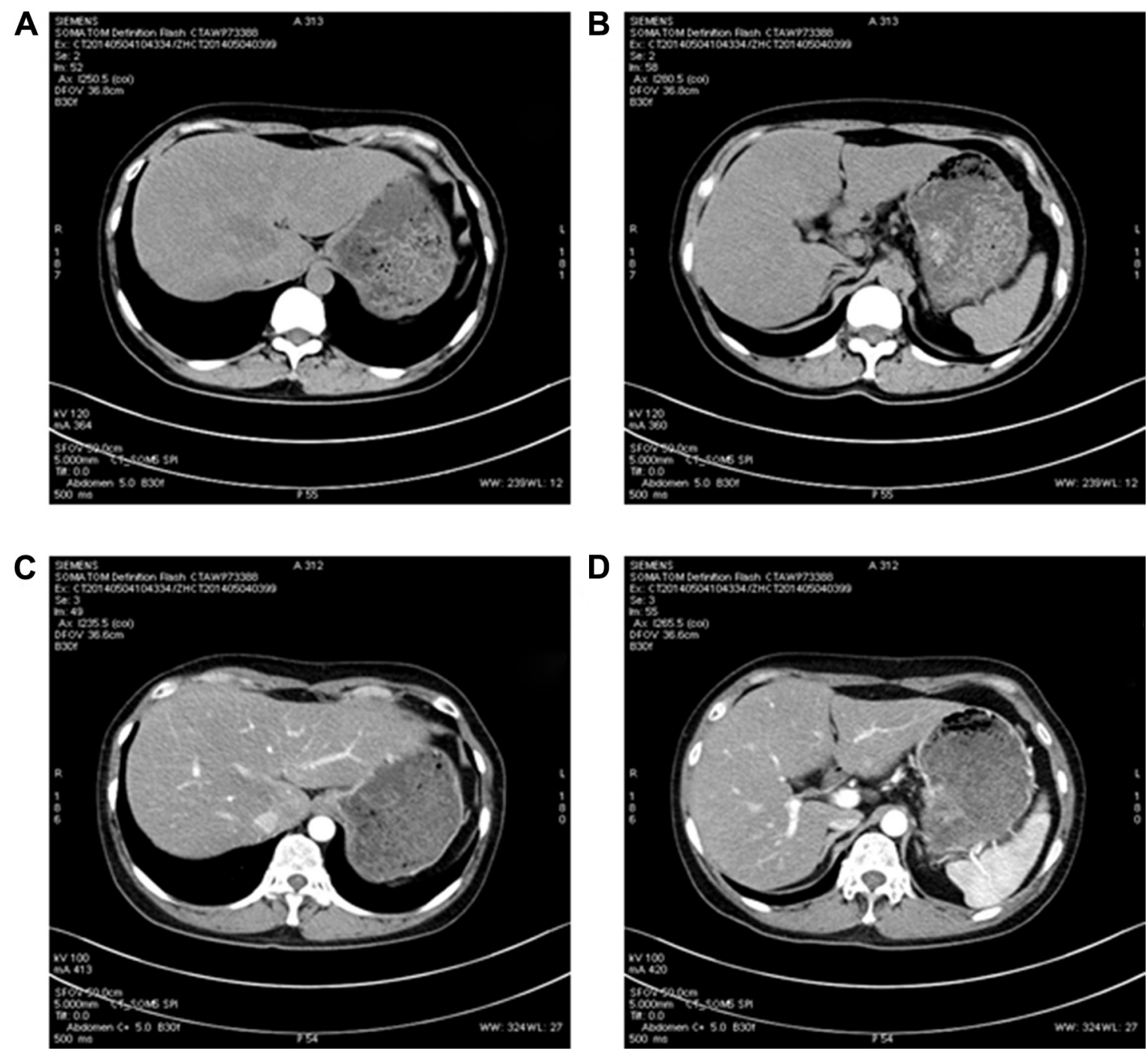

Figure 3 Post-therapy abdominal CT of the patient with hepatic metastasis in May 20I4.

Note: With 20 months of treatment, the hepatic lesions were further reduced in both (A and $\mathbf{B})$ plain scan and $(\mathbf{C}$ and $\mathbf{D})$ enhanced CT.

Abbreviation: $\mathrm{CT}$, computed tomography.

There was also some studies that showed no difference from other breast carcinomas with regard to prognosis and clinical presentation. ${ }^{36,37}$ Within our study, the number of patients with NEBC were too few to make a valuable survival analysis. However, for our included 10 patients with available clinical follow-up data, 70\% patients were alive free of disease and $30 \%$ are alive well with tumor, which presents a better prognosis in accordance with previous reports. Besides, two patients with disease progression after initial treatment still obtained a good effect in metastasis diseases, and they all alive without further progression of the disease. The outstanding treatment effects of these 2 patients might prove a well prognosis for NEBC patients even if they had distant metastasis. It could also provide more experience in this unusual disease.

It is also undeniable that there are a few limitations in our study. On the one hand, we could not collect sufficient number of patients because of a lack of NEBC. On the other hand, some patients were lost to follow-up and some patients had poor treatment compliance, which led us to obtain fewer available data. Hence, we could not make a significant conclusion.

\section{Conclusion}

NEBCs are a rare type of breast carcinomas and tend to occur in older women. They are more likely to be ER/PR positive and HER-2 negative. Particularly, immunohistochemical staining for neuroendocrine markers was extremely contributed to the confirmation of this uncommon cohort. The recognition of NEBC is limited, and the current treatment protocol is similar to general invasive breast carcinomas. Previous studies are still ambiguous with regard to the therapeutic regimen and long-term outcome. Our study retrospectively reviewed related literature and our own clinical 

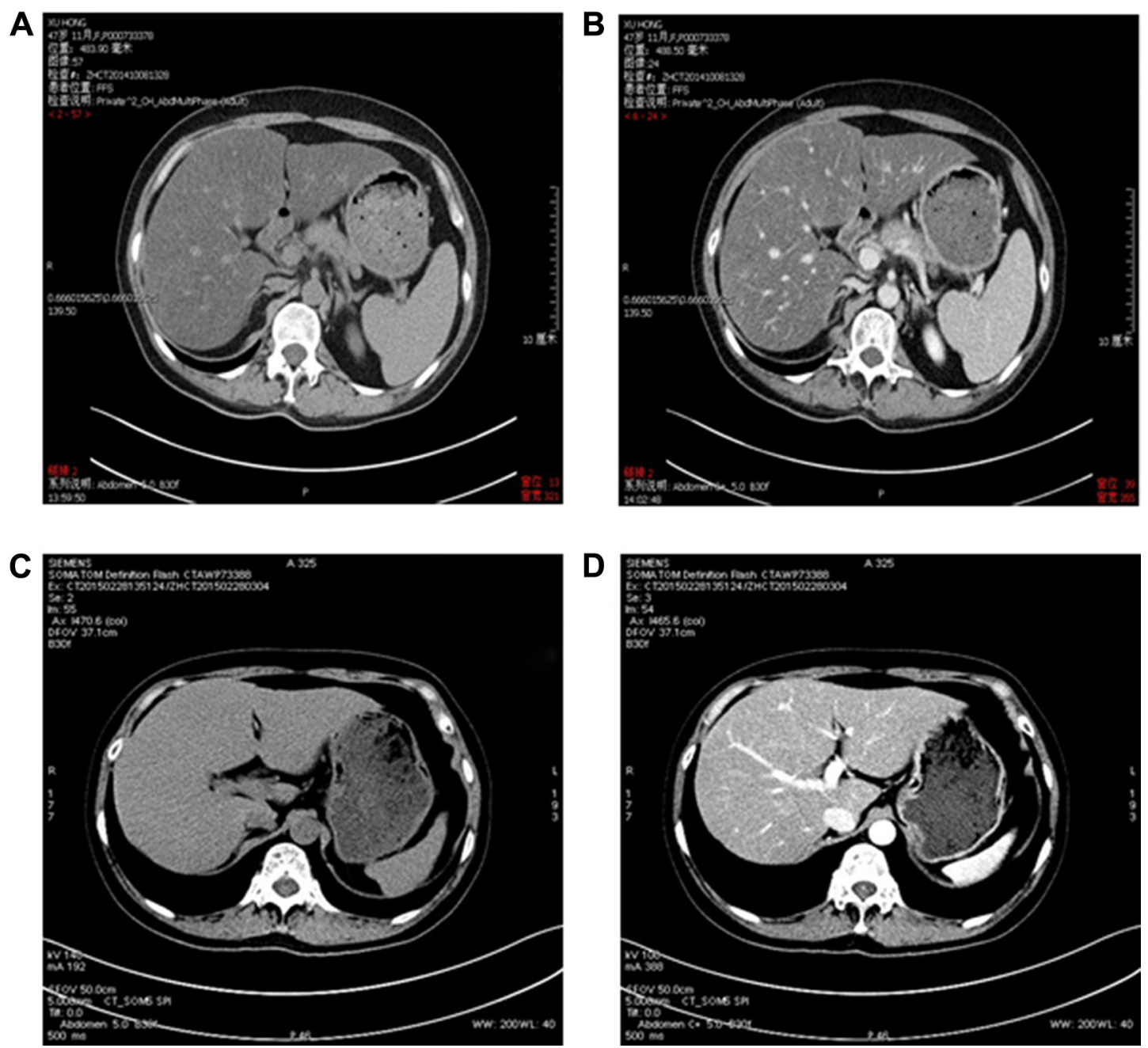

Figure 4 Surveillant $C T$.

Notes: (A and B) The CT of the abdomen showed that the hepatic metastasis lesions of this patient progressed again in October 20I4. (C and D) After a modified therapy, the reduction of hepatic lesions was obviously found by CT of the abdomen in February 2015.

Abbreviation: CT, computed tomography.

information and summarized clinical features, therapeutic strategies, and prognostic significance of NEBC, which might be helpful to increase knowledge of NEBC. However, more evidence should be provided to enhance the understanding of diagnosis, treatment, and prognosis for NEBC.

\section{Acknowledgments}

This work was supported in part by the Pathology Department of Chongqing Medical University and the medical records and statistics room of the First Affiliated Hospital of Chongqing Medical University. Thanks for their data support. This work was also supported by grants from the National Natural Science Foundation of China (NSFC, 81272265 and 81472658, URL: http://www.nsfc.gov.cn/). The funders had no role in study design, data collection and analysis, decision to publish, or preparation of the manuscript.

\section{Disclosure}

The authors report no conflicts of interest in this work.

\section{References}

1. Solcia E, kloppel G, Sobin LH. World Health Organization international histological classification of tumours: histological typing of endocrine tumours: second edition. Clin Endocrinol. 2000;53(2):259-259.

2. Hauser H, Wolf G, Uranus S, Klimpfinger M. Neuroendocrine tumours in various organ systems in a ten-year period. Eur J Surg Oncol. 1995;21(3): 297-300

3. Modlin IM, Lye KD, Kidd M. A 5-decade analysis of 13,715 carcinoid tumors. Cancer. 2003;97(4):934-959.

4. Modlin IM, Oberg K, Chung DC, et al. Gastroenteropancreatic neuroendocrine tumours. Lancet Oncol. 2008;9(1):61-72.

5. Lopez-Bonet E, Alonso-Ruano M, Barraza G, Vazquez-Martin A, Bernado L, Menendez JA. Solid neuroendocrine breast carcinomas: incidence, clinico-pathological features and immunohistochemical profiling. Oncol Rep. 2008;20(6):1369-1374.

6. Feyrter F, Hartmann G. On the carcinoid growth form of the carcinoma mammae, especially the carcinoma solidum (gelatinosum) mammae. Frankf Z Pathol. 1963;73:24-39. 
7. Cubilla AL, Woodruff JM. Primary carcinoid tumor of the breast: a report of eight patients. Am J Surg Pathol. 1977;1(4):283-292.

8. Tavassoli FA, Deyilee P. Tumors of the Breast and Female Genital Organ: Pathology and Genetics. Lyon: IARC Press; 2003.

9. Lakhani SR, Ellis IO, Schnitt SJ, Tan PH, van de Vijver MJ, editors. World Health Organization Classification of Tumours of the Breast. 4th ed. Lyon: IARC Press; 2012.

10. Papotti M, Macri L, Finzi G, Capella C, Eusebi V, Bussolati G. Neuroendocrine differentiation in carcinomas of the breast: a study of 51 cases. Semin Diagn Pathol. 1989;6(2):174-188.

11. Rovera F, Masciocchi P, Coglitore A, et al. Neuroendocrine carcinomas of the breast. Int J Surg. 2008;6(suppl 1):S113-S115.

12. Wei B, Ding T, Xing Y, et al. Invasive neuroendocrine carcinoma of the breast: a distinctive subtype of aggressive mammary carcinoma. Cancer. 2010;116(19):4463-4473.

13. Tang F, Wei B, Tian Z, et al. Invasive mammary carcinoma with neuroendocrine differentiation: histological features and diagnostic challenges. Histopathology. 2011;59(1):106-115.

14. Edge SB, Byrd DR, Compton CC, Fritz AG, Greene FL, Trotti A, editors. AJCC Cancer Staging Manual. 7th ed. New York, NY: Springer; 2010.

15. Gunhan-Bilgen I, Zekioglu O, Ustun EE, Memis A, Erhan Y. Neuroendocrine differentiated breast carcinoma: imaging features correlated with clinical and histopathological findings. Eur Radiol. 2003; 13(4):788-793.

16. Jeon $\mathrm{CH}$, Kim SM, Jang M, et al. Clinical and radiologic features of neuroendocrine breast carcinomas. J Ultrasound Med. 2014;33(8): $1511-1518$.

17. Tan PH, Schnitt SJ, van de Vijver MJ, Ellis IO, Lakhani SR. Papillary and neuroendocrine breast lesions: the WHO stance. Histopathology. 2015;66(6):761-770.

18. Kwon SY, Bae YK, Gu MJ, et al. Neuroendocrine differentiation correlates with hormone receptor expression and decreased survival in patients with invasive breast carcinoma. Histopathology. 2014;64(5): 647-659.

19. Ishida M, Umeda T, Abe H, Tani T, Okabe H. Neuroendocrine carcinoma of the breast with a mucinous carcinoma component: a case report with review of the literature. Oncol Lett. 2012;4(1):29-32.

20. Tanaka N, Katayama K, Negishi T, Kano H, Uchida N, Kuwano H. Case of breast cancer with endocrine differentiation. Int Surg. 2007; 92(4):214-217.

21. Makretsov N, Gilks CB, Coldman AJ, Hayes M, Huntsman D. Tissue microarray analysis of neuroendocrine differentiation and its prognostic significance in breast cancer. Hum Pathol. 2003;34(10):1001-1008.

22. Rovera F, Lavazza M, La Rosa S, et al. Neuroendocrine breast cancer: retrospective analysis of 96 patients and review of literature. Int J Surg. 2013;11(suppl 1):S79-S83.

23. Adams RW, Dyson P, Barthelmes L. Neuroendocrine breast tumours: breast cancer or neuroendocrine cancer presenting in the breast? Breast. 2014;23(2):120-127.
24. Richter-Ehrenstein C, Arndt J, Buckendahl AC, et al. Solid neuroendocrine carcinomas of the breast: metastases or primary tumors? Breast Cancer Res Treat. 2010;124(2):413-417.

25. Sica G, Wagner PL, Altorki N, et al. Immunohistochemical expression of estrogen and progesterone receptors in primary pulmonary neuroendocrine tumors. Arch Pathol Lab Med. 2008;132(12):1889-1895.

26. Perry KD, Reynolds C, Rosen DG, et al. Metastatic neuroendocrine tumour in the breast: a potential mimic of in-situ and invasive mammary carcinoma. Histopathology. 2011;59(4):619-630.

27. Christie M, Chin-Lenn L, Watts MM, Tsui AE, Buchanan MR. Primary small cell carcinoma of the breast with TTF-1 and neuroendocrine marker expressing carcinoma in situ. Int J Clin Exp Pathol. 2010;3(6): 629-633.

28. Chu P, Wu E, Weiss LM. Cytokeratin 7 and cytokeratin 20 expression in epithelial neoplasms: a survey of 435 cases. Mod Pathol. 2000;13(9): 962-972.

29. Cloyd JM, Yang RL, Allison KH, Norton JA, Hernandez-Boussard T, Wapnir IL. Impact of histological subtype on long-term outcomes of neuroendocrine carcinoma of the breast. Breast Cancer Res Treat. 2014; 148(3):637-644.

30. Wang J, Wei B, Albarracin CT, Hu J, Abraham SC, Wu Y. Invasive neuroendocrine carcinoma of the breast: a population-based study from the surveillance, epidemiology and end results (SEER) database. BMC Cancer. 2014;14:147.

31. Yildirim Y, Elagoz S, Koyuncu A, Aydin C, Karadayi K. Management of neuroendocrine carcinomas of the breast: a rare entity. Oncol Lett. 2011;2(5):887-890.

32. Berruti A, Saini A, Leonardo E, Cappia S, Borasio P, Dogliotti L. Management of neuroendocrine differentiated breast carcinoma. Breast. 2004;13(6):527-529.

33. Saeed A, Rehman A, Zaidi SA, Shaukat T, Jamil K, Abdullah K. Neuroendocrine carcinoma of breast. J Coll Physicians Surg Pak. 2011;21(6): 371-373.

34. Tse GM, Ma TK, Chu WC, Lam WW, Poon CS, Chan WC. Neuroendocrine differentiation in pure type mammary mucinous carcinoma is associated with favorable histologic and immunohistochemical parameters. Mod Pathol. 2004;17(5):568-572.

35. Zekioglu O, Erhan Y, Ciris M, Bayramoglu H. Neuroendocrine differentiated carcinomas of the breast: a distinct entity. Breast. 2003;12(4): 251-257.

36. Sapino A, Papotti M, Righi L, Cassoni P, Chiusa L, Bussolati G. Clinical significance of neuroendocrine carcinoma of the breast. Ann Oncol. 2001;12(suppl 2):S115-S117.

37. Miremadi A, Pinder SE, Lee AH, et al. Neuroendocrine differentiation and prognosis in breast adenocarcinoma. Histopathology. 2002;40(3): 215-222. 


\section{Supplementary materials}

Table SI Mammography features of NEBC

\begin{tabular}{|c|c|c|c|c|c|c|c|}
\hline Number & Presentation & Location & Shape & Margins & Density & Calcification & BI-RADS \\
\hline 1 & Mass & LUOQ & Round & Indistinct & High & Clustered & $4 C$ \\
\hline 2 & Mass & LUOQ & Round & Indistinct & High & None & $4 \mathrm{~B}$ \\
\hline 3 & Mass & LLOQ & Oval & Well defined & High & None & 0 \\
\hline 4 & Mass & LUIQ & Oval & Well defined & High & None & $4 B$ \\
\hline 5 & Nondetectable & & & & & & 0 \\
\hline 6 & Mass & LLOQ & Irregular & Circumscribed & High & Micro & $4 \mathrm{~A}$ \\
\hline 7 & Mass & LU & Irregular & Indistinct & High & Micro & $4 \mathrm{C}$ \\
\hline 8 & Nondetectable & & & & & & \\
\hline 9 & Unknown & & & & & & \\
\hline 10 & Distortion & RUOQ & Not obvious & Indistinct & Isodensity & Needle like & 5 \\
\hline 11 & Calcification & RUOQ & Not obvious & Not obvious & High & Sand like & 6 \\
\hline 12 & Mass & LUOQ & Irregular & Spiculate & High & None & 5 \\
\hline 13 & Not done & & & & & & \\
\hline 14 & Mass & LUOQ & Irregular & Indistinct & High & Sand like & Unknown \\
\hline 15 & Mass & RUOQ & Lobulated & Spiculate & High & None & 6 \\
\hline
\end{tabular}

Abbreviations: NEBC, neuroendocrine breast carcinoma; BI-RADS, Breast Imaging-Reporting and Data System; LUOQ, left upper outer quadrant; LLOQ, left lower outer quadrant; LUIQ, left upper inner quadrant; LU, left upper; RUOQ, right upper outer quadrant.

Table S2 Ultrasonography features of NEBC

\begin{tabular}{|c|c|c|c|c|c|c|}
\hline Number & Shape & Margins & Echogenicity & Calcification & Color Doppler & $\begin{array}{l}\text { Lymph node } \\
\text { enlargement }\end{array}$ \\
\hline I & Round & Indistinct & Hypoechoic & Punctiform & Increased blood supply & Yes \\
\hline 2 & Round & Indistinct & Hypoechoic & None & None & No \\
\hline 3 & Oval & Well defined & Hypoechoic & None & High-velocity blood flow & Yes \\
\hline 4 & Oval & Well defined & Hypoechoic & None & High-velocity blood flow & Yes \\
\hline 5 & Irregular & Indistinct & Hypoechoic & None & None & No \\
\hline 6 & Irregular & Indistinct & Heterogeneous & None & Increased blood supply & Yes \\
\hline 7 & Irregular & Spiculate & Heterogeneous & None & None & No \\
\hline 8 & Irregular & Crab like & Heterogeneous & None & Increased blood supply & No \\
\hline 9 & Unknown & & & & & \\
\hline 10 & Lobulated & Indistinct & Heterogeneous & Clustered & Increased blood supply & Yes \\
\hline II & Oval & Indistinct & Heterogeneous & None & None & Yes \\
\hline 12 & Irregular & Indistinct & Heterogeneous & Punctiform & Increased blood supply & Yes \\
\hline 13 & Not done & & & & & \\
\hline 14 & Irregular & Crab like & Heterogeneous & None & Increased blood supply & No \\
\hline 15 & Irregular & Crab like & Heterogeneous & Punctiform & Increased blood supply & No \\
\hline
\end{tabular}

Abbreviation: NEBC, neuroendocrine breast carcinoma.

OncoTargets and Therapy

\section{Publish your work in this journal}

OncoTargets and Therapy is an international, peer-reviewed, open access journal focusing on the pathological basis of all cancers, potential targets for therapy and treatment protocols employed to improve the management of cancer patients. The journal also focuses on the impact of management programs and new therapeutic agents and protocols on patient perspectives such as quality of life, adherence and satisfaction. The manuscript management system is completely online and includes a very quick and fair peer-review system, which is all easy to use. Visit http://www.dovepress.com/testimonials.php to read real quotes from published authors. 